


\section{B I B L I O T H E C A SCRIPTORVM GRAECORVM ET ROMANORVM \\ T E V B N E R I A N A}

1702 


\title{
POETAE ELEGIACI
}

\section{TESTIMONIA ET FRAGMENTA}

\author{
EDIDERVNT \\ BRVNO GENTILI ET CAROLVS PRATO \\ EDITIO STEREOTYPA \\ EDITIONIS ALTERIVS \\ NOVIS SIMONIDIS FRAGMENTIS AVCTAE \\ (MMII)
}

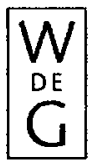

BEROLINI ET NOVI EBORACI WALTER DE GRUYTER MMVIII 


\section{(@) Gcdruckt auf säurcfrcicm Papicr, das die US-ANSI-Norm über Haltbarkeit erfüllt.}

ISBN 978-3-598-71702-4

\section{Bibliografische Information der Deutschen Nationalbibliothek}

Die Deutsche Nationalbibliothek verzeichnet diese Publikation in der Deutschen Nationalbibliografic; detaillierte bibliografische Daten sind im Internct über http://dnb.d-nb.de abrufbar.

(C) Copyright 2008 by Walter de Gruyter GmbH \& Co. KG, D-10785 Berlin Dicses Werk einschlicßlich aller seiner Teile ist urheberrechtlich geschützt. Jede Verwertung außcrhalb der engen Grenzen des Urheberrechtsgesetzes ist ohne Zustimmung des Verlages unzulässig und strafbar. Das gilt insbesonderc für Vervielfältigungen, Übersetzungen, Mikroverfilmungen und die Einspeicherung und Verarbeitung in elektronischen

Systemen.

\section{Printed in Germany}

Druck und Bindung: AZ Druck und Datentechnik GmbH, Kempten 